\title{
Computer simulations of global memory models
}

\author{
IAN NEATH \\ Purdue University, West Lafayette, Indiana
}

\begin{abstract}
Computer simulation models of memory-including the so-called global memory models-have had and continue to have a profound impact on current memory research and theory. Unfortunately, no memory textbooks published before 1998 present these models to students. The arguments for and against these types of models are summarized along with reasons why the models should be taught at both the undergraduate and graduate levels. A set of freely available computer programs that can facilitate classroom presentation is then briefly described.
\end{abstract}

While simple qualitative conceptual models have proved very useful, one eventually reaches a point at which some form of detailed and preferably quantitative model is necessary if the concepts are to develop.

$$
\text { -Alan Baddeley (1994, p. 363) }
$$

In cognitive psychology, as well as in other related areas, quantitative models are increasing in both popularity and sophistication. In particular, there are several models of memory that are usually referred to as global memory models (Raaijmakers \& Shiffrin, 1992): They attempt to model, in a formal, quantitative fashion, human memory in a variety of different tasks and settings. Although these models typically began by focusing on recall and recognition, many have been applied to other, very different, paradigms, including association priming (Ratcliff \& McKoon, 1995) and false memory (Arndt \& Hirshman, 1997). In this paper, I briefly summarize arguments for and against the increased use of formal-and especially computer simulation-models, argue that these models should be taught at both the undergraduate and graduate levels, and then discuss one way of presenting these models to undergraduates and graduates.

\section{PROS AND CONS OF SIMULATION MODELING}

The debate over the merits of simulation and mathematical modeling is neither new (see, e.g., Atkinson, Bower, \& Crothers, 1965; Dutton \& Starbuck, 1971) nor completely resolved (see, e.g., Hintzman, 1991; Lewandowsky, 1993). Many of the criticisms of simulation models also apply to other forms of theory development: "A theory based on fundamentally incorrect notions is still a bad theory, no matter what its degree of mathematical formalism" (Atkinson et al., 1965, p. 4). However, certain

Correspondence should be addressed to I. Neath, 1364 Psychological Sciences Building, Purdue University, West Lafayette, IN 479071364 (e-mail: neath@psych.purdue.edu). costs and benefits of simulation modeling in particular have been consistently identified.

One potential problem is known as Bonini's paradox, where a model is created that is so complex that one "cannot pinpoint the explicit causal mechanism in the model" (Dutton \& Starbuck, 1971,p. 4). Such a model is of little use in understanding the original phenomenon because the model itself is not well understood. A related problem is that it is quite easy to maintain an enormous, complex simulation model that provides appropriate output even when the ideas and concepts embedded in the model are fundamentally incorrect. Loftus (1985), for example, has speculated on what would have happened if Johannes Kepler had had a computer simulation of the Ptolemaic universe. Under such a system, the addition of extra epicycles would be trivial and the predictive accuracy of the model would be maintained. The accuracy of the model would likely have deterred development of competing heliocentric systems.

A second criticism has been termed the irrelevantspecification problem (Lewandowsky, 1993). When a theory is implemented as a simulation model, there are many programming choices that need to be made to translate a (usually) underspecified verbal theory into a set of instructions that a serial computer will execute. Lewandowsky's example concerns implementing the statement "select the best match." If serial comparisons are made, one can choose the $<$ operator or the $\leq$ operator to find a comparison that minimizes some error term. Both operators satisfy the "select the best match" guideline, but the difference between $<$ and $\leq$ can lead to different results. Consider the case where two (or more) items result in the same error score: The $<$ operator will cause the first item compared to be selected, whereas the $\leq$ operator will cause the last item compared to be selected. Only the computer code itself unambiguously describes the model.

A third criticism is the problem of inadvertent performance. "The fact that a program is sufficient to produce its outputs is no guarantee that the outputs derive from 
the model-builders' assumptions; ... simulations have been published in which the outputs were almost entirely independent of the model-builders' conceptual models" (Dutton \& Starbuck, 1971, p. 4). As one recent example, Lewandowsky (1993) cited Rumelhart and McClelland's (1986) connectionist model of children's acquisition of past tense. It turns out that the model produced the appropriate effects of overregularization only because of the input set; if a different set of inputs is used, the model does not produce this result.

The most common reason cited in support of the use of simulation models is that programming a computer requires a precise specification of all assumptions and processes (Atkinson et al., 1965; Lewandowsky, 1993). Modern-day computers simply will not run unless all the information is provided. To program a global memory model, every step-from acquisition to retrieval - must be described in detail. Although this does not guarantee that the assumptions are correct, or even useful, it does guarantee that at least there are a sufficient number of statements for the model to run.

A second common reason is that such models provide a check on human reasoning, particularly when there are a number of processes that can interact (Atkinson et al., 1965). Hintzman (1991, p. 41) has provided an example concerning a reasonable-sounding statement made by some researchers: Men have more sexual partners than women. "It is clear from the context that this does not hinge on the slight plurality of women to men (which would make it trivial), and that homosexual partners do not count. I challenge anyone to set up a formal model consistent with the claim-that is, there must be equal numbers of men and women, but men must have more heterosexual partners than women do." A related benefit of computer simulation models is that they enable more complex systems to be instantiated, such as current connectionist, PDP, or neural network models. William James (1890/1983) provided a diagram of a connectionist system back in 1890, Thorndike's (1913) model of learning was called connectionism, and Hull (1943) proposed a complete instantiation of such a system. Although connectionist models existed well before the advent of computers, they did not really advance much until computers became more widely available. "The Hullians did not invent modern PDP systems, of course. But they might have, if they had owned Sun workstations or a Cray" (Hintzman, 1993, p. 375).

A third reason for using simulation models is that several models have actually led to serendipitous findings, several of which have been documented by Lewandowsky (1993). His examples concern analytic rather than simulation models, but serendipity can also appear for the latter class. For example, the feature model (Nairne, 1990) accounts for the effects of articulatory suppression by positing that the irrelevant articulation adds noise to the memory trace. It accounts for the suffix effect by having features of the suffix overwrite features of the final list item. By accident, the model was run with both articulatory suppression and suffix effect options speci- fied, and it predicted a suffix effect even under articulatory suppression. A review of the literature showed no previous reports, and a subsequent empirical investigation upheld the prediction (Surprenant, LeCompte, \& Neath, in press). Presumably, no previous researchers had conducted the experiment because no extant theory of articulatory suppression addressed suffix effects. The feature model was not built to address this particular situation, but it made a prediction that no one had previously thought of testing.

Finally, a simulation model can serve as a powerful existence proof (Atkinson et al., 1965). Perhaps the most well known of these concerns a proposed division of memory. Tulving (1983) distinguished between two separate memory systems, episodic and semantic memory; part of the evidence supporting this distinction comes from dissociations in which an experimenter demonstrates that certain variables have different effects on each presumed system (Tulving \& Schacter, 1990). MINERVA 2 (Hintzman, 1984) offers an explanation of memory for individual experiences (i.e., episodic memory) and memory for abstract concepts (i.e., generic or semantic memory) within a single system. Although MINERVA 2 stores only individual episodes, abstractions and other "semantic memory" phenomena can be constructed through the combined responses of the traces that are most strongly activated. The model thus proves that it is possible to account for the data without positing separate memory systems. This does not prove that one view or the other is correct; it does, however, prove that the unitary position is at least as viable as the multiple systems view.

The consensus, then, is that a simulation model, like a purely verbal model, is inherently neither good nor bad. Rather, the utility of a model-verbal, mathematical, or simulation-depends on its ability to offer plausible explanations and predictions for psychological phenomena.

\section{WHY TEACH THE GLOBAL MEMORY MODELS?}

I believe that it is critically important to teach simulation models-especially SAM, TODAM, and MINERVA 2-to both undergraduate and graduate students. First, these models have had and continue to have an enormous impact on the study of memory. For example, according to the Social Science Citation Index, in 1996 there were more citations to each of these models than to the classic model of Atkinson and Shiffrin $(1968,1971)$; the same is true for 1997. If citation rate is used as an index, each of these global memory models is more influential in the current memory literature than is the older modal model. Despite this influence on the field, only one memory textbook includes a presentation of all of the former models; all current memory texts, however, mention the Atkinson and Shiffrin model. ${ }^{2}$ For undergraduate students, especially, primary sources may not be all that useful: These models were developed over a series of papers, most of which appeared in Psychological Review, and there are few sources that explain the general 
properties of the models. Unless students are exposed to these models in class, they will miss a major set of theories of memory.

A second reason to use these models is that they can serve as a pedagogical tool to introduce students to the critical study of simulation models in general. Given that this sort of model development will only continue to increase, it is imperative that students be able to distinguish stronger models from weaker models. One part of this is learning how to separate the critical assumptions from the less important; indeed, many of the assumptions that lie behind a particular model are largely irrelevant. For example, many models hold that information can be represented as an ordered series of $+1 \mathrm{~s}$ and $-1 \mathrm{~s}$. No modeler would be upset to find that people do not represent information as a vector of $\pm 1 \mathrm{~s}$; a different code could be substituted and the model would remain unaffected (Hintzman, 1991). On the other hand, assumptions about the composition of certain subsets of items in memory can profoundly affect a model's performance (Nairne \& Neath, 1994).

A final advantage of including these models in a course on memory is that when presented with these models, students can learn how to decode the written and mathematical descriptions that appear in articles and how to translate these into a set of model properties. The underlying ideas of each of these models are quite simple; it is the detailed, step-by-step operation that becomes complex. One argument I commonly hear against teaching these models is that they are beyond the scope of undergraduates. This is simply not true. I routinely cover a subset of these models in my undergraduate memory course at Purdue: With an appropriate set of teaching materials, undergraduates can and do understand each of these models.

\section{PRESENTING SIMULATION MODELS}

Teaching the global memory models can be very difficult because of the lack of appropriate tools. A compounding problem is that many students (and indeed, many faculty, including the current author) do not think well using only symbolic mathematical terms. It can be difficult to see how the model works, let alone reason through novel predictions or situations in which several parameters change simultaneously. As a reaction to this, I included a chapter devoted to the global memory models in a recent memory text (Neath, 1998).

The general idea behind that chapter was to present a summary of three of the most prominent global memory models: SAM, which stands for search of associative memory (Gillund \& Shiffrin, 1984; Raaijmakers \& Shiffrin, 1981); MINERVA 2, which is the second version of a model named after the Greek goddess of wisdom (Hintzman, 1984, 1986, 1987, 1988); and TODAM, which stands for theory of distributed associative memory (Hockley \& Murdock, 1987; Lewandowsky \& Murdock, 1989; Murdock, 1982, 1983, 1993). ${ }^{3}$
For each of these models, the text presents the relevant key equations, offers a verbal translation of these, and describes the important assumptions. Each model addresses recognition and some form of recall (free recall for SAM, cued recall for MINERVA 2, and serial recall for TODAM). After presenting the basic overview, the chapter describes one important property for each model. Rather than presenting all the myriad findings that each model can simulate, the chapter emphasizes one or two areas. For SAM, the emphasis is on explaining dissociations between free recall and recognition; for MINERVA 2, the emphasis is on explaining effects of both episodic and semantic memory within a single system; and for TODAM, the emphasis is on illustrating that a distributed memory system, where all information is stored in a common vector, can account for a substantial portion of human memory data.

A detailed discussion in a chapter, however, may not be sufficient to convey all of the important properties of these models. Thus, there is an instructor's supplement that describes several computer programs and suggests simulations that students can run to further explore the properties of the models. ${ }^{4}$ Each model comes in two versions: a version for Apple Macintosh computers that runs on machines with a 68020 or higher processor and that also runs native on PowerPC computers, and a version for IBM-compatible computers that runs on machines with a 286 or higher processor. Each program has a consistent, easy-to-use interface. The program prompts for all parameters and specifies not only the possible range but also the typical (or default) value. To illustrate the general approach, the program for SAM will be presented in some detail. (To avoid confusion, the term $S A M$ will refer to the model and $S A M 1.0$ will refer to the computer program.)

SAM's properties are determined, in large part, by the setting of four key parameters. Each of these parameters corresponds to a psychological concept involving the strength of a particular kind of association: $a$ is used with context associations, $b$ with interitem strengths, $c$ with associations between an item and itself, and $d$ with residual or preexisting associations. Figure 1 shows the effect of each of these parameters on both recognition (top panel) and free recall (bottom panel) when all other parameters are held constant. The text describes the reasons why each parameter affects performance in the way that it does. For example, larger values of $c$ lead to more self associations; by increasing associations between the item and itself, recognition performance improves because the familiarity of the target distribution is increased with no change in the distractor distribution. In free recall, on the other hand, an increase in $c$ reduces performance because self-sampling is increased. Self-sampling decreases performance because when an item is used as a cue, it samples itself rather than another item in the list.

As useful as this figure is, there is a problem determining the effects of changing more than one parameter 

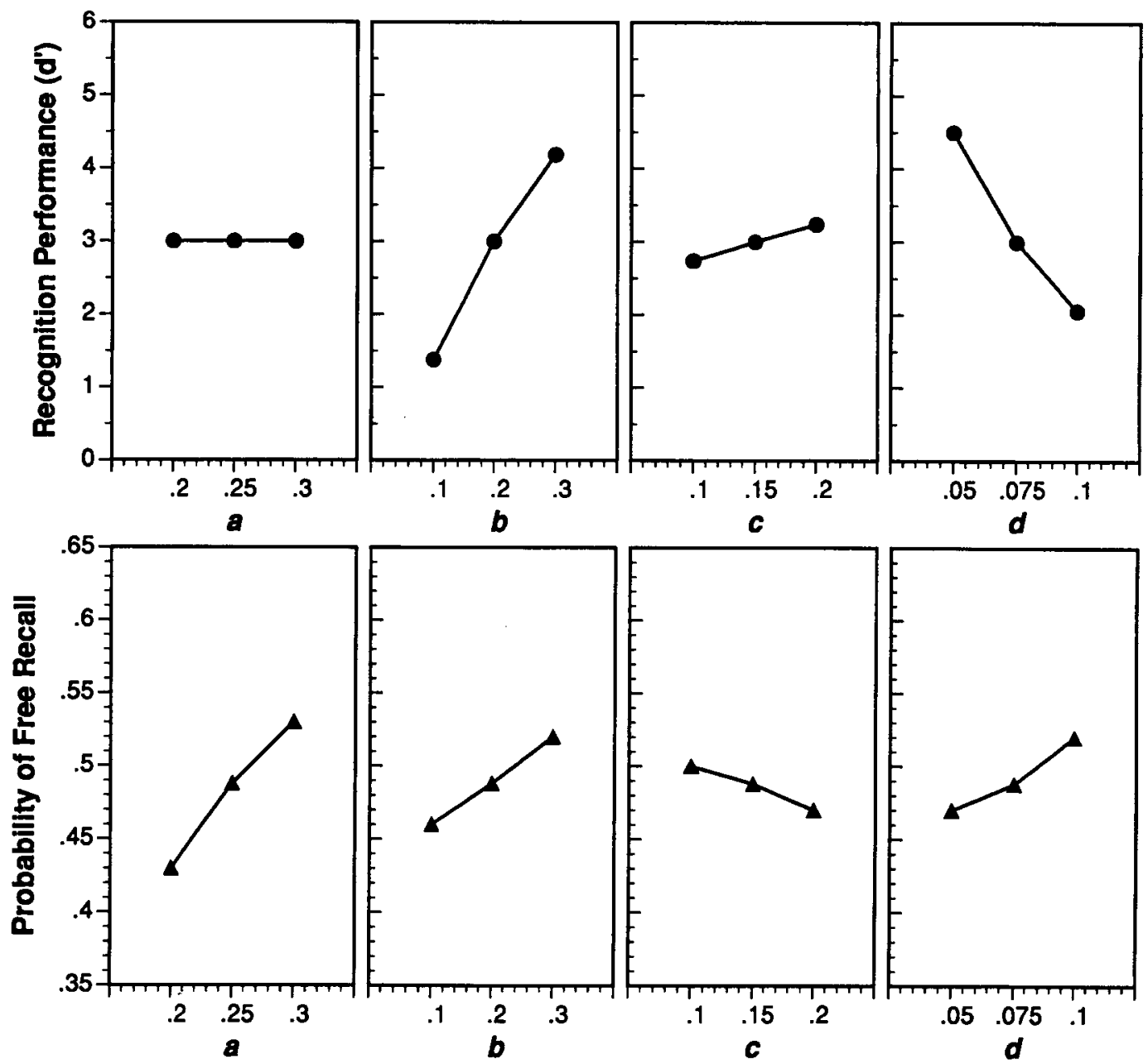

Figure 1. The effects of varying just $a, b, c$, or $d$ when all other parameters are held constant on recognition and recall in SAM. From "A retrieval model for both recognition and recall," by G. Gillund and R. M. Shiffrin, 1984, Psychological Review, 91, pp. 20-21. Copyright 1984 by Publisher. Adapted with permission.

at a time. This is where the software is useful, particularly if the instructor has access to a fast machine and a screen projection system. One of the strengths of SAM is that it can simulate the different effects of word frequency on recall and recognition. This requires changing several parameters simultaneously. It is easier to generate associations between high-frequency words than between low-frequency words; thus, $b$ (the parameter representing the strength of the interitem associations) will be larger, and $d$ (which represents residual or preexisting associations) will be larger for high-frequency items than for low-frequency items. Figure 1 reveals that increasing $b$ has the same effect on recognition and recall whereas increasing $d$ has opposite effects. The problem for the student is determining the relative tradeoff. This is where the computer programs are an excellent pedagogical tool. The simulation can be run using several levels of each parameter, and the effects can be immediately assessed. Table 1 presents a summary of the results.

Depending on the speed of the computer, SAM 1.0 can easily be run in class with the results immediately ap- parent. For example, a student may wonder whether it is necessary to change a particular setting, or what happens if one is not changed. The answer can be (almost) immediate and precise. A second use is as an outside assignment; assignments can be made where the student runs the program on his/her personal computer or in a computer lab. The software described may be freely copied and distributed for this purpose. The instructor's supplement contains suggestions for several assignments for each model. By actually changing the parameter settings and seeing the direct results, the students get a better appreciation for the abilities and limitations of the model.

Table 1

Simulation Results Using SAM 1.0 for Recognition and Recall of a 20-Item List of High- or Low-Frequency Words Presented at a Rate of 1 Item Every 2 Sec

\begin{tabular}{ccccccc}
\hline Condition & Hit Rate & False Alarm & $d^{\prime}$ & Recall & $b$ & $d$ \\
\hline High frequency & .921 & .044 & 3.118 & .479 & .20 & .075 \\
Low frequency & .954 & .012 & 3.931 & .424 & .10 & .035
\end{tabular}

Note - Parameters not shown were at their default settings. 
SAM 1.0 (PPC)

Compiled at 07:46:14 on May 221997.

Programmed by Ian Neath (neath@psych.purdue.edu)

Copyright (C 1997 Ian Neath All rights reserved

Which version of SAM? $(1=$ Recall or $2=$ Recognition, default $=$ recall $)$ 2

Load saved parameter settings? $(1=$ Yes or $2=$ No $)$

Context $(\mathrm{a})=0.250$

New value $[0.0$ to 1.0$]$ :

Item $(b)=0.200$.

New value $[0.0$ to 1.0$]$ :

Self $(c)=0.150$.

New value $[0.0$ to 1.0$]$ :

Residual $(\mathrm{d})=0.075$

New value $[0.0$ to 1.0$]$ :

Noise index $(v)=0.500$

New Value $[0.0$ to 1.0$]$

Presentation Time $(\mathrm{t})=2.000$

New value $[0$ to 10$]$ :

Buffer Size $(r)=4$.

New value [ 1 to 10$]$ :

List Length (LL) $=20$.

New value [1 to 40$]$ :

Recognition Criterion (Beta) $=0.973$

New value [0 to 10]

$\mathrm{Kmax}=30$

New value [ 1 to 1000 ]:

Lmax $=8$

New value [1 to 1000 ]:

Number of Simulations $=1000$.

New value [ 1 to 10000 ]

Save these settings? $(1=$ Yes or $2=$ No, default $=$ No $)$

Enter the name of the output file (sam.out)

Simulation began Sat Oct 25 12:17:56 1997

Parameter Settings:

Number of simulations $=1000$

$\mathrm{a}=0.250$

$\mathrm{b}=0.200$

$\mathrm{c}=0.150$

$\mathrm{d}=0.075$

$\mathrm{v}=0.500$

$\mathrm{t}=2.000$

$r=4$

$\mathrm{LL}=20$

Beta $=0.973$

$\mathrm{K} \max =30$

$\mathbf{L} \max =8$

Hold down control and press 'c' to abort...

Simulation number 100 of 1000

Simulation number 200 of 1000

Simulation number 300 of 1000

Simulation number 400 of 1000

Simulation number 500 of 1000

Simulation number 600 of 1000

Simulation number 700 of 1000

Simulation number 800 of 1000

Simulation number 900 of 1000

Simulation number 1000 of 1000

Hits: $\quad 0.944$

False Alarms: 0.070

d': $\quad 3.065$

Mean target: $\quad 1.327$

Mean distractor: 0.804

Simulation completed Sat Oct 25 12:17:58 1997

Figure 2. A sample session running SAM 1.0 showing all information that is displayed on the screen.
Because these programs were intended to be used by a broad range of people, some of whom may have relatively little experience with computers, the interface was designed to be simple, portable, and convenient. Figure 2 shows a sample run with SAM 1.0; this figure shows the information as presented on the screen of the computer. The first choice is to select the recall or recognition version of SAM. For each question, the program lists all possible responses and also lists the default response. Simply pressing the Return or Enter key enters the default value. If a value outside of the specified range is entered, the software automatically replaces the illegal value with the default value.

SAM 1.0 offers the ability to use a previously saved set of parameters. Usually, a person is interested in the effects of changing only a small number of parameters. Rather than having to enter all parameter values each time through, the user can press the return key and use the saved values. If the user indicates that he/she wishes to use a saved set, the program will load the most recently saved set of parameters; these are stored in a file called samprefs.dat. If this file does not exist, the program will create it using the default settings.

The user will then be prompted with a list of parameters, the current setting, and an opportunity to change them. For each item, pressing the Return key accepts the current value. The permissible range is shown in the brackets. If a value that is not legal or is out of range is entered, the current value is used instead. In Figure 2, the default values were used for every parameter. When the simulation begins, all the parameters are listed and their setting is shown. Every 100 iterations, the program updates its status to show that it is still running; finally, the output is shown. For recognition, SAM 1.0 provides the hit and false alarm rates along with a calculated value of $d^{\prime}$. (Chapter 10 in Neath, 1998-the chapter immediately prior to the one on global memory models-provides an explanation of $d^{\prime}$ and signal detection theory as applied to recognition memory). The algorithm used to calculate $d^{\prime}$ is the one proposed by Brophy (1986) and should be accurate for all but very extreme hit and false alarm rates. Also shown are the means of the distractor and target distributions. SAM 1.0 automatically saves all of the information from the screen to disk; depending on the program and the simulation, extra information may also provided.

TODAM 1.0 is much like SAM 1.0 in that each type of simulation is determined by the setting of various parameters. MINERVA 21.0 is slightly different. This program has far fewer parameters, and so different paradigms are simulated by using different probe vectors and by assembling different sets of items in memory. Thus, the first step is selecting one of six different simulations (see Figure 3). Depending on the simulation selected, the relevant parameters and options are displayed. The actual operation of the program is consistent with the other two programs. For each, the supplement describes the simulation options, explains the output, and provides simulations that students can use to explore each model. 
MINVERA 21.0 (PPC)

Compiled at 10:25:57 on Jul 281997.

Programmed by Ian Neath (neath@psych.purdue.edu)

Copyright (C) 1997 Ian Neath All rights reserved

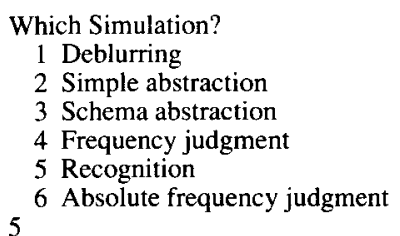

Number of subjects $=20$.

New value [1 to 5000]: 1000

Learning parameter $(\mathrm{L})=0.500$.

New value [0 to 1.0]:

Number of features $(\mathrm{N})=20$.

New value [1 to 50$]$ :

Number of old traces $(M)=20$

New value [ 1 to 50$]$ :

Number of new items $=20$.

New value [0 to 50$]$ :

Criteria $\mathrm{c} 1=0.050$

New value $[-2$ to 5$]$ :

Simulation began Mon Nov 3 07:30:03 1997

Hit rate $\quad 0.803$

False alarm rate 0.111

d' $\quad 2.076$

Mean I (old items) 0.153

Mean I (new items) 0.000

Simulation completed Mon Nov 3 07:30:17 1997

Figure 3. A sample session running MINERVA 21.0 simulating recognition.

\section{Availability}

The software described may be obtained free of charge for educational use from http://www.psych.purdue.edu/ $\sim$ neath/memory/memory.html. There are two versions of each, one for Apple Macintosh and one for IBMcompatible computers. Also at that site is a set of suggested simulations for each model, as well as descriptions and explanations of all output from the models. Although these materials were designed to accompany a textbook (Neath, 1998), purchase of the textbook is not required.

\section{REFERENCES}

ANDERSON, J. R. (1993). Rules of the mind. Hillsdale, NJ: Erlbaum. ARndT, J., \& Hirshman, E. (1997). Applying MINERVA 2 to false recognition. Abstracts of the Psychonomic Society, 2, 46.

Atkinson, R. C., Bower, G. H., \& Crothers, E. J. (1965). An introduction to mathematical learning theory. New York: Wiley.

Atkinson, R. C., \& Shiffrin, R. M. (1968). Human memory: A proposed system and its control processes. In K. W. Spence \& J. T. Spence (Eds.), The psychology of learning and motivation (Vol. 2, pp. 89-195). New York: Academic Press.

Atkinson, R. C., \& Shiffrin, R. M. (1971). The control of short-term memory. Scientific American, 225, 82-90

BADDElEY, A. D. (1994). Working memory: The interface between memory and cognition. In D. L. Schacter \& E. Tulving (Eds.), Memory systems 1994 (pp. 351-367). Cambridge, MA: MIT Press.

BRoPHY, A. L. (1986). Alternatives to a table of criterion values in signal detection theory. Behavior Research Methods, Instruments, \& Computers, 18, 285-286.
Dutton, J. M., \& Starbuck, W. H. (Eds.) (1971). Computer simulation of human behavior. New York: Wiley.

EsTES, W. K. (1972). An associative basis for coding and organization in memory. In A. W. Melton \& E. Martin (Eds.), Coding processes in human memory (pp. 161-190). Washington, DC: Winston.

EsTEs, W. K. (1997). Processes of memory loss, recovery, and distortion. Psychological Review, 104, 148-169.

Gillund, G., \& Shiffrin, R. M. (1984). A retrieval model for both recognition and recall. Psychological Review, 91, 1-65.

GregG, L. W., \& Simon, H. A. (1967). Process models and stochastic theories of simple concept formation. Journal of Mathematical Psychology, 4, 246-276.

HINTZMAN, D. L. (1984). MINERVA 2: A simulation model of human memory. Behavior Research Methods, Instruments, \& Computers, 16, 96-101.

HINTZMAN, D. L. (1986). "Schema abstraction" in a multiple-trace memory model. Psychological Review, 93, 411-428.

HINTZMAN, D. L. (1987). Recognition and recall in MINERVA 2: Analysis of the 'recognition-failure' paradigm. In P. E. Morris (Ed.), Modeling cognition (pp. 215-229). Chichester, U.K.: Wiley.

HiNTZMAN, D. L. (1988). Judgments of frequency and recognition memory in a multiple-trace memory model. Psychological Review, 95, 528-551.

HiNTZMAN, D. L. (1991). Why are formal models useful in psychology? In W. E. Hockley \& S. Lewandowsky (Eds.), Relating theory and data: Essays in honor of Bennet B. Murdock (pp. 39-56). Hillsdale, NJ: Erlbaum.

Hintzman, D. L. (1993). Twenty-five years of learning and memory: Was the cognitive revolution a mistake? In D. E. Meyer \& S. Kornblum (Eds.), Attention and performance XIV: Synergies in experimental psychology, artificial intelligence, and cognitive neuroscience (pp. 359-391). Cambridge, MA: MIT Press.

HoCKLEY, W. E., \& MURDOCK, B. B. (1987). A decision model for accuracy and response latency in recognition memory. Psychological Review, 94, 341-358.

Hull, C. L. (1943). Principles of behavior. New York: AppletonCentury-Crofts.

JAMES, W. (1983). The principles of psychology. Cambridge, MA: Harvard University Press. (Original work published 1890)

LEWANDOWSKY, S. (1993). The rewards and hazards of computer simulations. Psychological Science, 4, 236-243.

LeWANDOWsKy, S., \& Murdock, B. B. (1989). Memory for serial order. Psychological Review, 96, 25-57.

LoFTUS, G. (1985). Johannes Kepler's computer simulation of the universe: Some remarks about theory in psychology. Behavior Research Methods, Instruments, \& Computers, 17, 149-156.

MCClelland, J. L., \& RumelhaRT, D. E. (1989). Explorations in parallel distributed processing: $A$ handbook of models, programs, and exercises. Cambridge, MA: MIT Press.

Medin, D. L., \& Ross, B. H. (1997). Cognitive psychology (2nd ed.). Fort Worth: Harcourt Brace.

MuRDocK, B. B. (1982). A theory for the storage and retrieval of item and associative information. Psychological Review, 89, 609-626.

MuRDOCK, B. B. (1983). A distributed memory model for serial-order information. Psychological Review, 90, 316-338

MURDOCK, B. B. (1993). TODAM2: A model for the storage and retrieval of item, associative, and serial-order information. Psychological Review, 100, 183-203.

NaIRNE, J. S. (1990). A feature model of immediate memory. Memory \& Cognition, 18, 251-269.

NAIRNE, J. S., \& NEATH, I. (1994). A critique of the retrieval/deblurring assumptions of TODAM. Psychological Review, 101, 528-533.

Neath, I. (1998). Human memory: An introduction to research, data, and theory. Pacific Grove, CA: Brooks/Cole.

NeATH, I., \& NaIRNE, J. S. (1995). Word-length effects in immediate memory: Overwriting trace decay theory. Psychonomic Bulletin \& Review, 2, 429-441

RaAijmakers, J. G. W., \& Shiffrin, R. M. (1981). Search of associative memory. Psychological Review, 88, 93-134.

RaAijmakers, J. G. W., \& Shiffrin, R. M. (1992). Models for recall and recognition. Annual Review of Psychology, 43, 205-234. 
Ratcl.jF, R., \& McKoon, G. (1995). Sequential effects in lexical decision: Tests of compound-cue retrieval theory. Journal of Experimental Psychology: Learning, Memory, \& Cognition, 21, 1380-1388.

Rumel haRT, D. E., \& MCClelland, J. L. (1986). On learning the past tense of English verbs. In J. L. McClelland, D. E. Rumelhart, \& the PDP Research Group (Eds.), Parallel distributed processing: Explorations in the microsinucture of cognition (Vol.2, pp. 216-271). Cambridge, MA: MIT Press.

Social Science Citation Index (1996). Philadelphia: ISI

SurPrenant, A. M., LeCompte, D. C., \& Neath, I. (in press). Manipulations of irrelevant information: Suffix effects with articulatory suppression and irrelevant speech. Quarterly Journal of Experimental Psychology.

THORNDIKE, E. L. (1913). The psychology of learning. New York: Teachers College.

Tulving, E. (1983). Elements of episodic memory. New York: Oxford University Press.

Tulving, E., \& SCHacter, D. L. (1990). Priming and human memory systems. Science, 247, 301-306.

\section{NOTES}

1. In this paper, I focus on simulation models. Some of the cited benefits and problems were originally directed at mathematical or analytic models, but apply equally well to simulations. Although I emphasize the similarities, there are important differences among these methods of modeling (Dutton \& Starbuck, 1971; Gregg \& Simon, 1967) and even for a particular model, there can be differences between the analytic version and computer simulation version (Lewandowsky \& Murdock, 1989).

2. Some cognitive psychology texts do mention models like SAM (e.g., Medin \& Ross, 1997); however, these books present SAM only at a verbal level of description. It is still curious, however, that exposure to the global memory models occurs only in lower level courses.

3. There are many models that could be classified as global memory models (Raaijmakers \& Shiffrin, 1992). SAM, TODAM, and MINERVA 2 were selected for the first edition of the text because they are the most influential of these models. Another influential model, ACT-R (Anderson, 1993), already has an extensive website (http://act.psy. cmu.edu), and there are also good sources for connectionist models (McClelland \& Rumelhart, 1989).

4. In addition to the three global memory models, there are also implementations of Estes's $(1972,1997)$ perturbation model and Naime's (1990; Neath \& Nairne, 1995) feature model.

(Manuscript received November 3, 1997; revision accepted for publication April 8, 1998.) 